\title{
A rare case of isolated cysticercosis of the biceps brachii muscle: a diagnostic dilemma
}

\author{
Prasad Chaudhari, Rajendraprasad R Butala, Sanjay Dhar and Manit Arora* \\ *Correspondence: manit_arora@hotmail.com \\ CrossMark \\ Department of Orthopaedics, Padmashree Dr DY Patil Hospital and Research Centre, Navi Mumbai, India.
}

\begin{abstract}
Cysticercosis is an infection with the larval form of the pork tapeworm Taenia solium that commonly presents with central nervous system involvement. Isolated muscular involvement is rare with only a handful of cases reported in the literature. Involvement of the biceps brachii muscle is rarer with only two such cases reported. We present a case of isolated cysticercosis of the biceps brachii muscle that presented a diagnostic challenge. Misdiagnosed on ultrasound but diagnosed correctly on Magnetic Resonance (MR) imaging, the patient's infection was successfully managed non-operatively with oral antihelminthic and symptomatic treatment.
\end{abstract}

Keywords: Cysticercosis, tapeworm, muscle, biceps brachii, albendazole, anti-inflammatory medication, MRI

\section{Introduction}

Cysticercosis infection in humans is caused by the pork tapeworm T. solium [1]. In order of frequency, the occurrence of cysts in humans is the central nervous system, the eye, striated muscle, subcutaneous tissue, and rarely, other tissues [1]. Most muscular cases are associated with central nervous system involvement, presence of multiple muscular cysts or both [2]. Isolated muscular involvement is rare [3] and because of the non-specific symptoms it presents a diagnostic dilemma for the treating physician. Till date there are only a handful of cases of isolated muscular cysticercosis reported in the literature [2-13], with involvement of the biceps being even rarer $[3,6]$. We present a case of isolated cysticercosis of the biceps muscle, which presented a diagnostic dilemma, was accurately diagnosed by Magnetic Resonance (MR) imaging and successfully treated non-operatively with oral anthelminthic medication and symptomatic management with a focus on anti-inflammatory cover. To our knowledge, this is only the third such reported case in the literature and the first to be managed successfully non-operatively without oral steroid cover.

\section{Case report}

An otherwise healthy, right-hand dominant, 36-year-old, male, manual laborer presented to our institution with pain and swelling of one month's duration in the right upper limb post an episode of heavy lifting at work.

The patient had been lifting heavy weights at work one month ago when he noticed pain in the right upper arm. Later that night, the patient started having swelling to the same region and attributed his symptoms to a muscular sprain. The patient managed his symptoms with benign neglect. On presentation to our institution, the patient had been suffering with dull, aching, mid-upper arm pain radiating to the elbow region made worse by activities involving the right arm and relieved by rest, and swelling to the same. The pain and swelling had showed a slight increase during the duration of illness. The patient had not suffered any constitutional symptoms such as fever, night sweats, fatigue, weight loss or anorexia during this period. The patient's physical status was good and his medical and family histories were insignificant. The patient was a non-vegetarian with consumption of poultry and fish once a fortnight, but no history of pork or beef consumption. The patient denied any contact with animals or farms, and lived in a middle class residential neighborhood not suffering any recent epidemics of T. solium.

On physical examination there was no obvious swelling in the area of interest; however, there was erythema to the overlying skin on the antero-medial aspect of the arm (Figure 1). Tenderness was localized to the antero-medial aspect of the mid-upper right arm. Deep palpation revealed a soft to firm globular swelling $2 \times 3 \mathrm{~cm}$ with indistinct margins. The mass was non-pulsatile and non-adherent to the skin. There was no change in the nature of swelling with movement of the elbow joint. The Speed's test and Yergason's test localized pain to the area of interest but not to the bicipital groove. There was no local warmth or erythema. Range of motion of the elbow and 

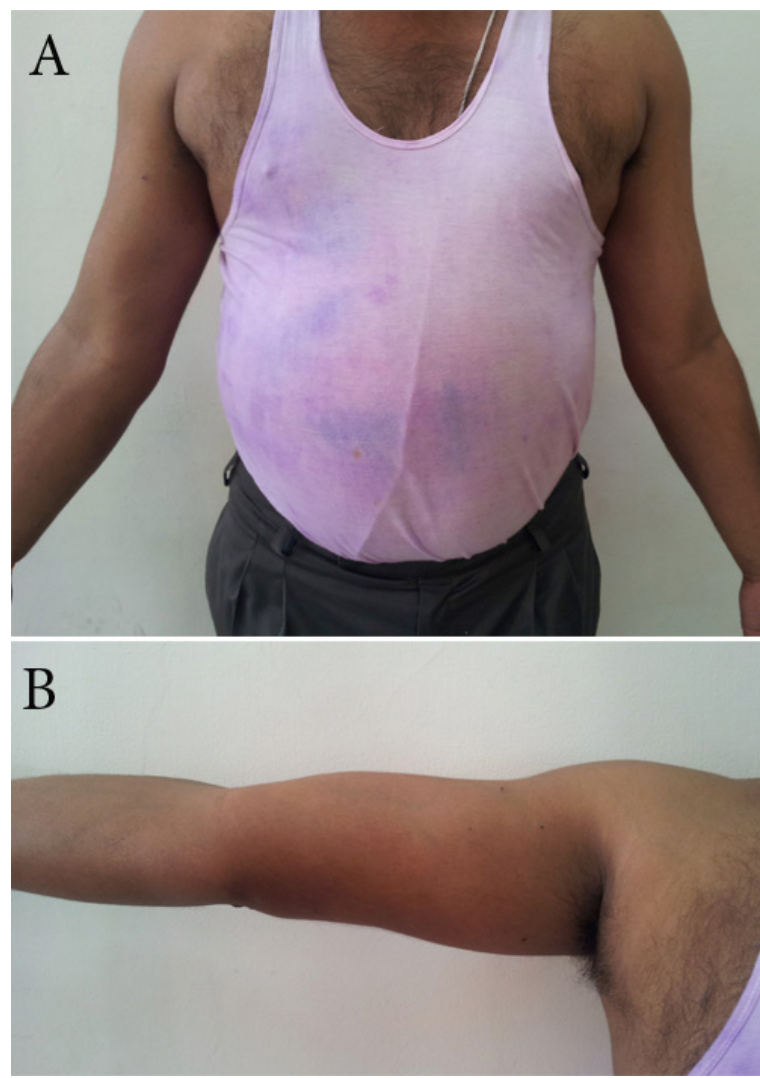

Figure 1. Clinical photograph of patient's affected upper extremity.

shoulder joints were within normal limits and there was no evidence of distal neurovascular deficit.

Laboratory investigations were essentially normal with no evidence of anemia or leukocytosis. Eosinophilia was present with a value of $10 \%$ of the total leukocyte count. The ESR was elevated $(95 \mathrm{~mm} / \mathrm{hr})$ and the C-reactive protein was slightly elevated (12.0). Stool examination for ova/cysts was negative. Radiograph of the upper extremity showed no obvious abnormalities (Figure 2). Ultrasound examination (Figure 3) was reported as being consistent with a resolving biceps brachii muscle tear within the substance of the muscle. Accordingly, the patient was managed non-operatively with symptomatic treatment, however, there was nil relief of symptoms over a period of one week. In view of this, MR imaging (Figure 4) was carried out revealing cysticercosis of the biceps brachii muscle. Titer of ELISA for T. solium was raised (>1:400). It was necessary to rule out presence of cysts in more frequently involved and important sites. CT scan of the brain and eyes revealed no cysts.

The patient was managed conservatively with oral antihelminthic medication (oral albendazole $15 \mathrm{mg} / \mathrm{kg} / \mathrm{day}$ divided into two doses daily for 3 weeks) and symptomatic treatment (trypsin and chymotrypsin, diclofenac and pantoprazole). The patient was followed up every alternate

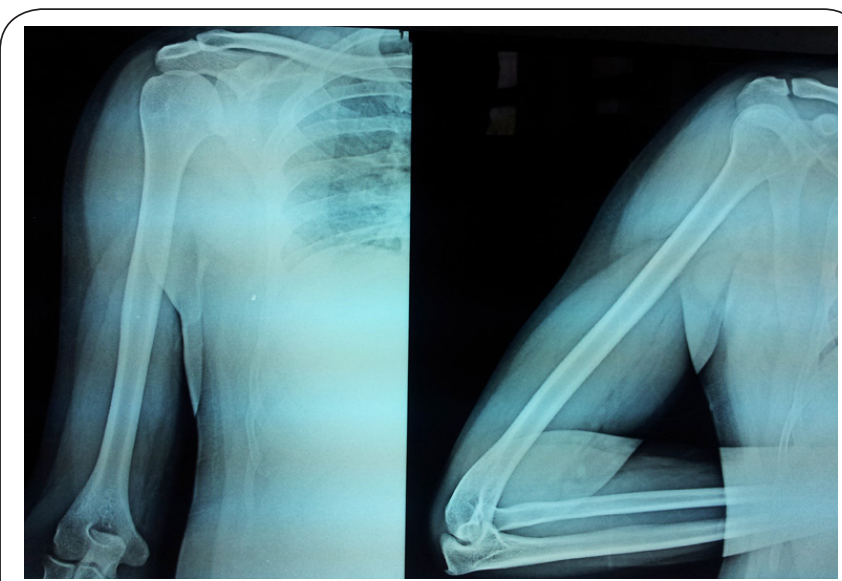

Figure 2. Antero-posterior and lateral radiograph of the right humerus.

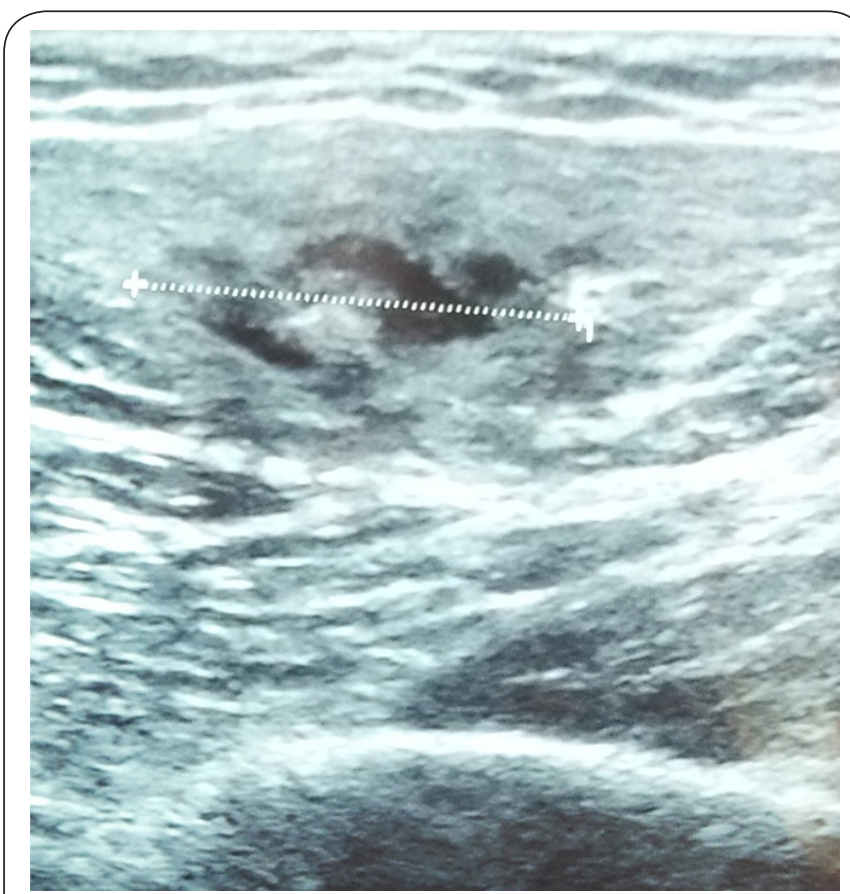

Figure 3. Ultrasound of right biceps muscle demonstrating focal lesion within the muscle mass, consistent with a? resolving biceps brachii muscle tear.

day for the first week and then weekly thereafter for 3 weeks. Patient showed initial symptomatic relief from the second day of treatment and at the end of four weeks there was complete resolution of the swelling on palpation and the patient was essentially symptom free. On follow up at 5 months the patient had been managing well with activities of daily living and reported no further symptoms.

\section{Discussion}

Cysticercosis infection in humans is caused by the pork tapeworm T. solium [1]. This condition is endemic to countries 

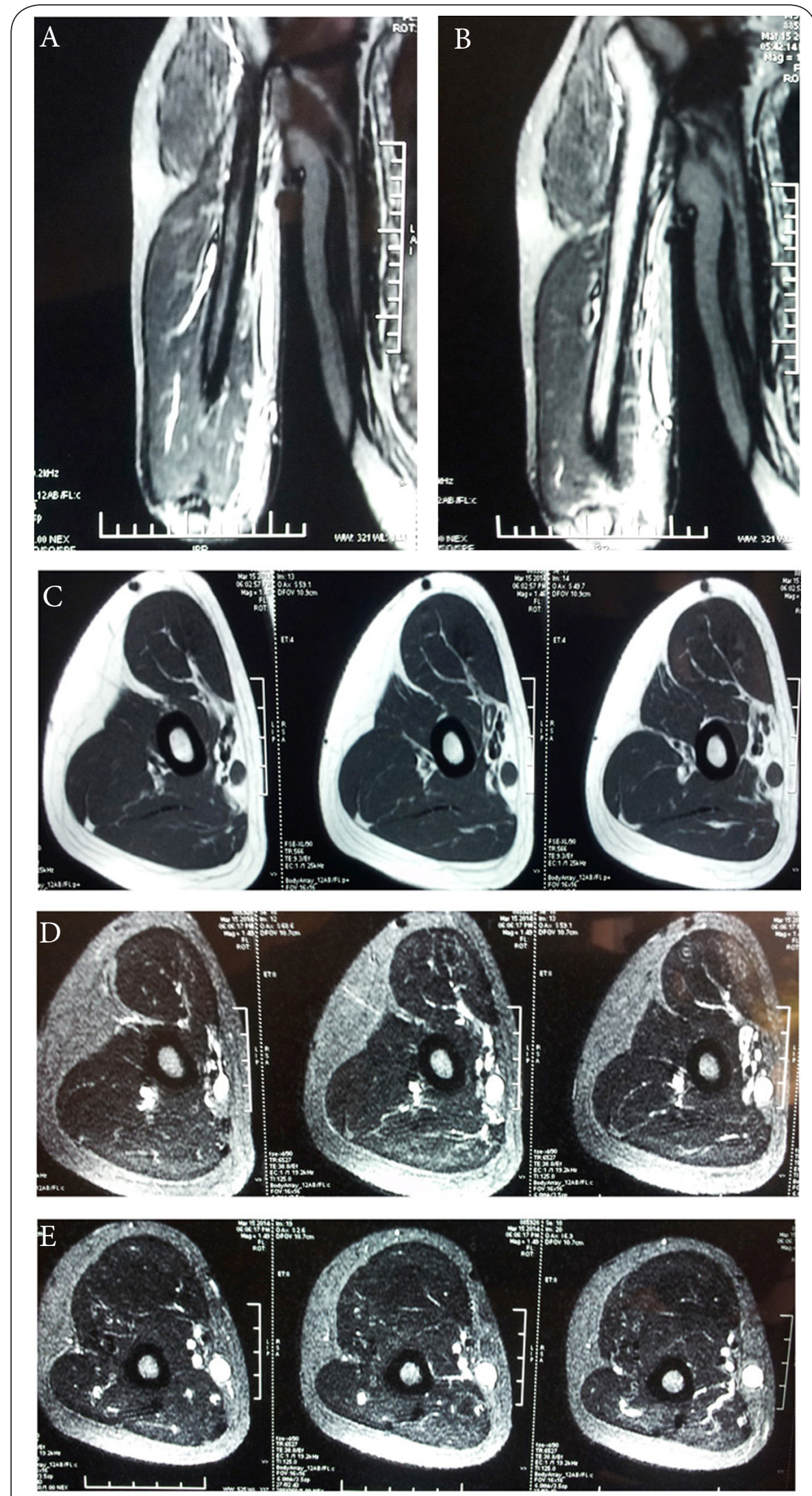

Figure 4. T1 and T2 weighted MR images in coronal and axial planes demonstrating isolated muscular cysticercosis of the biceps brachii muscle. 
such as India and African nations [14] where poor hygiene practices are still common and where pigs are raised as a food source within or adjacent to populated areas. The cases of this potentially fatal infection in the west may be related to immigration and the increase in travel to tropical countries [15]. Normally, humans are the definitive hosts for T. solium, the life cycle of which begins with ingestion of viable larvae in inadequately cooked pork.

Ingested eggs hatch in the small intestine, releasing oncospheres that penetrate the bowel mucosa and enter the bloodstream to travel to various tissues where they develop to form an encysted larval form of T. solium known as cysticercosis cellulosae. When the larva dies, it induces an aggressive granulomatous inflammatory response, leading to characteristic organ-specific symptoms.

The occurrence of cysts in humans in order of frequency is the central nervous system, the eye, striated muscle, subcutaneous tissue, subcutaneous tissue, and rarely, other tissues. Most muscular cases are associated with central nervous system involvement, presence of multiple muscular cysts or both [2]. Isolated muscular involvement is rare [3] and because of the non-specific symptoms it presents a diagnostic dilemma for the treating physician. Till date there are only a handful of cases of isolated muscular cysticercosis reported in the literature [2-13], with involvement of the biceps being even rarer $[3,6]$. In our case, we too faced a diagnostic challenge due to the rarity of this presentation.

Most muscular cysticercosis is asymptomatic and goes unnoticed for the life of the patient. Rarely, after the death of a worm in the cyst or trauma to the cyst there is release of antigens from the cyst, which excites the beforementioned inflammatory response. In our case, it is possible that heavy lifting led to micro-trauma to the region of cyst which subsequently induced the release of antigens.

Three different clinical manifestations of muscular cysticercosis are described: myalgic myopathic type; the nodular or mass like type; and the pseudohypertrophy type in which multilocular cyst formation occurs in group of muscle $[16,17]$. The myalgic type results from death of the cyst and leakage of fluid leading to inflammation. The nodular type or pseudotumor type both result from degeneration of the cyst and slow intermittent leakage of fluid over time, leading to a chronic inflammatory response with collection of fluid around the cyst producing a mass. Our case was characteristic of the myalgic variant.

Del Brutto et al., (2008) proposed diagnostic criteria for human cysticercosis [18]. They suggested that apart from immunochemical studies (including detection of anticysticercal antibodies), CT and MRI are important tools in diagnosis. Although MRI is more specific for neurocysticercosis, CT may be the modality of choice for muscle cysts as it can demonstrate multiple cysts in a honeycomb or leopard skin pattern against a background of muscle mass [19].

Treatment of cysticercosis depends on the site of involvement.
Isolated muscular or subcutaneous cysticercosis require no specific treatment unless it is painful, which may necessitate excision. Recently, case reports have advocated non-operative management, even for painful masses, with antihelminthic medication and oral steroid therapy $[6,17,20]$. In our case, the patient refused operative excision and steroid therapy due to an upcoming family wedding in his native village. Accordingly, we instituted only oral antihelminthic (albendazole) and symptomatic treatment, with success.

Albendazole acts by inhibiting microtubule formation. The loss of cytoplasmic microtubules blocks glucose uptake in the larval and adult stages of the parasites, thereby depleting their energy reserves and causing death. Steroids are commonly used as a cover for the inflammatory response to the necrotic pathway. The success of our treatment strategy without oral steroid cover suggests that lower strength anti-inflammatory medications may be sufficient as a cover to the inflammatory response. We recommend this as a treatment option to avoid the side effects of steroid therapy.

\section{Conclusion}

Isolated muscular cysticercosis is a diagnostic dilemma for treating physicians and may present in a variety of forms. We present a rare case of isolated cysticercosis in the biceps brachii muscle. To our knowledge, this is only the third such case reported in the literature. We successfully managed the patient with a combination of albendazole and symptomatic treatment with a focus on anti-inflammatory cover.

\section{Competing interests}

The authors declare that they have no competing interests.

Authors' contributions

\begin{tabular}{|l|c|c|c|c|}
\hline Authors' contributions & PC & RRB & SD & MA \\
\hline Research concept and design & -- & -- & -- & $\checkmark$ \\
\hline Collection and/or assembly of data & -- & -- & -- & $\checkmark$ \\
\hline Data analysis and interpretation & -- & - & - & $\checkmark$ \\
\hline Writing the article & -- & -- & -- & $\checkmark$ \\
\hline Critical revision of the article & -- & -- & -- & $\checkmark$ \\
\hline Final approval of article & $\checkmark$ & $\checkmark$ & $\checkmark$ & $\checkmark$ \\
\hline Statistical analysis & -- & -- & -- & $\checkmark$ \\
\hline
\end{tabular}

\section{Publication history}

Editor: Keqiang Chen, Virginia Polytechnic Institute and State University, USA.

Received: 02-May-2014 Final Revised: 08-Jul-2014

Accepted: 11-Jul-2014 Published: 26-Jul-2014

\section{References}

1. Garcia $H H$, Gonzalez $A E$, Evans $C A$ and Gilman $R H$. Taenia solium cysticercosis. Lancet. 2003; 362:547-56. | Article I PubMed Abstract | PubMed Full Text

2. Ogilvie CM, Kasten P, Rovinsky D, Workman KL and Johnston JO. Cysticercosis of the triceps--an unusual pseudotumor: case report and review. Clin Orthop Relat Res. 2001; 217-21. I PubMed

3. Abdelwahab IF, Klein MJ, Hermann G and Abdul-Quader M. Solitary 
Chaudhari et al. Journal of Rheumatology and Orthopedics 2014, http://www.hoajonline.com/journals/pdf/2055-7000-1-3.pdf

cysticercosis of the biceps brachii in a vegetarian: a rare and unusual pseudotumor. Skeletal Radiol. 2003; 32:424-8. | Article | PubMed

4. Kumar BD, Dave B and Meghana SM. Cysticercosis of masseter. Indian J Dent Res. 2011; 22:617. | Article | PubMe

5. Kumar R, Singh V and Rastogi A. Cysticercosis of temporalis muscle: a case report. J Pediatr Neurol. 2005; 3:269-72.

6. Nagaraj C, Singh S, Joshi A and Trikha V. Cysticercosis of biceps brachii: a rare cause of posterior interosseous nerve syndrome. Joint Bone Spine. 2008; 75:219-21. | Article | PubMed

7. Sen K, Karmakar P, Bandyopadhyay A, Santra T and Sarkar M. Cysticercosis involving muscles and liver only: A yet unknown entity. Ann Trop Med Public Heal. 2013; 6:350. I Article

8. Sethi PK, Sethi NK, Torgovnick J and Arsura E. Cysticercosis of temporalis muscle: an unusual cause of temporal headaches. A case report. J Headache Pain. 2007; 8:315-6. | Article | PubMed Abstract | PubMed Full Text

9. Sharma R, Gautam P, Kumar S, Elhence P, Bansal R and Gupta G. Isolated cysticercosis cellulosae of sternocleidomastoid muscle: a case report with review of literature. Indian J Otolaryngol Head Neck Surg. 2011; 63:127-30. | Article | PubMed Abstract | PubMed Full Text

10. Singal R, Mittal A, Gupta S, Gupta R, Sahu P and Gupta A. Intramuscular cysticercosis diagnosed on ultrasonography in thigh: A rare case report. N Am J Med Sci. 2010; 2:162-4. | PubMed Abstract | PubMed Full Text

11. Yue $\mathrm{XH}$. Fine needle aspiration biopsy diagnosis of cysticercosis. A case report. Acta Cytol. 1994; 38:90-2. | PubMed

12. Singh S, Sreenivasan V, Garg K, Wazir ND, Rajput JS and Sandhu Virk $P$. Cysticercosis involving muscle of mastication: a review and report of two cases. Case Rep Dent. 2013; 2013:814126. | Article | PubMed Abstract | PubMed Full Text

13. Sharma SR, Sharma N and Yeolekar ME. Carpal tunnel syndrome caused by cysticercosis. Indian J Plast Surg. 2010; 43:210-2. | Article | PubMed Abstract | PubMed Full Text

14. Holzapfel BM, Schaeffeler C, Banke IJ and Waldt S. A 37-year-old man with a painless growing mass of the thorax. Clin Orthop Relat Res. 2010; 468:1193-8. | Article | PubMed Abstract | PubMed Full Text

15. Raimer $\mathrm{S}$ and Wolf JE, Jr. Subcutaneous cysticercosis. Arch Dermatol. 1978; 114:107-8. | Article | PubMed

16. Horton J. Biology of tapeworm disease. Lancet. 1996; 348:481. | Article I PubMed

17. Mittal A, Das D, Iyer N, Nagaraj J and Gupta M. Masseter cysticercosis - a rare case diagnosed on ultrasound. Dentomaxillofac Radiol. 2008; 37:113-6. | Article | PubMed

18. Del Brutto OH, Wadia NH, Dumas M, Cruz M, Tsang VC and Schantz PM. Proposal of diagnostic criteria for human cysticercosis and neurocysticercosis. J Neurol Sci. 1996; 142:1-6. | Article I PubMed

19. Bhalla A, Sood A, Sachdev A and Varma V. Disseminated cysticercosis: a case report and review of the literature. J Med Case Rep. 2008; 2:137. I Article | PubMed Abstract | PubMed Full Text

20. Mohan K, Saroha V, Sharma A, Pandav S and Singh U. Extraocular muscle cysticercosis: clinical presentations and outcome of treatment. J Pediatr Ophthalmol Strabismus. 2005; 42:28-33. | PubMed

\section{Citation:}

Chaudhari P, Butala RR, Dhar S and Arora M. A rare case of isolated cysticercosis of the biceps brachii muscle: a diagnostic dilemma. J Rheumatol Orthop. 2014; 1:3.

http://dx.doi.org/10.7243/2055-7000-1-3 